\title{
Conceptual fragmentation and the rise of eliminativism
}

\author{
Henry Taylor $^{1} \cdot$ Peter Vickers ${ }^{2}$
}

Received: 10 August 2015 / Accepted: 18 January 2016/Published online: 7 April 2016

(C) The Author(s) 2016. This article is published with open access at Springerlink.com

\begin{abstract}
Pluralist and eliminativist positions have proliferated within both science and philosophy of science in recent decades. This paper asks the question why this shift of thinking has occurred, and where it is leading us. We provide an explanation which, if correct, entails that we should expect pluralism and eliminativism to transform other debates currently unaffected, and for good reasons. We then consider the question under what circumstances eliminativism will be appropriate, arguing that it depends not only on the term in question, but also on the context of discussion and details of the debate at hand. The resultant selective eliminativism is an appealing compromise for various 'pluralists' and 'eliminativists' who are currently locking horns.
\end{abstract}

Keywords Eliminativism · Pluralism · Fragmentation · Concepts $\cdot$ Philosophy of science

\section{Introduction}

It is only a slight exaggeration to say that conceptual pluralism is taking over debates in (philosophy of) science. That is to say, important scientific concepts, long thought to have a single underlying meaning, are often now considered to have multiple distinct

Henry Taylor

jht30@cam.ac.uk

Peter Vickers

peter.vickers@durham.ac.uk

1 Faculty of Philosophy, University of Cambridge, Cambridge, UK

2 Department of Philosophy, University of Durham, Durham, UK 
meanings no one of which is 'correct' or 'best'. Let us make this claim concrete right away with a list of examples:

1. SPECIES. The concept SPECIES ${ }^{1}$ has been understood in importantly different ways throughout the history of biology, and contrary definitions have competed in the literature. But in the last thirty years or so pluralism has prevailed as the dominant opinion: there are various different species concepts which are all important, and no one of which is privileged. The most prominent examples are BIOSPECIES, ECOSPECIES, and PHYLOSPECIES (see e.g. Kitcher 1984; Ereshefsky 1992a, b; Dupré 1993; Brigandt 2003), but recently the way that 'species' is defined in microbiology has also become an important consideration in this debate (Ereshefsky 2010a, b; Ereshefsky and Reydon 2015).

2. $A C I D$. For a very long time it was assumed as a given that there would be a single answer to the question 'What makes something an acid?', and different theories competed in the literature (see Thagard 1990 for a brief history). Gradually it came to be universally accepted that there are significantly different acid concepts - including the Arrhenius, Brönsted-Lowry, and Lewis conceptions of 'acid' - no one of which is 'best' or 'correct' (see Stanford and Kitcher 2000; Hendry 2005).

3. INTELLIGENCE. INTELLIGENCE is a classic case of a concept which was long thought to have a single meaning: intelligence tests were common and taken very seriously. Today 'intelligence' is usefully described as an umbrella term for many importantly different respects in which a human being might cognitively perform in a favourable way, including emotional awareness, social awareness, and IQ. Although pluralism about INTELLIGENCE is widely accepted, the extent of the plurality is much debated. Further, some have suggested that 'intelligence' really is only an umbrella term, such that 'general intelligence' does not exist in any significant sense (e.g. Howe 1990; Schlinger 2003).

4. RACE. Whether we are eliminativists or realists about the race concept, it is widely accepted that there are many different conceptions in the social sciences literature. $^{2} \mathrm{~A}$ few of the more prominent conceptions are: (i) cladistic race (which focusses on ancestry), (ii) biological race (with a focus on one or another feature of human biology - there are several options here), (iii) one or another 'purely social' conception of race, and (iv) a 'folk' conception of race. In academic circles, it is increasingly rare to see somebody argue that just one of these conceptions is 'correct' or 'best' in all contexts.

5. CONSCIOUSNESS. Ned Block (1995) describes CONSCIOUSNESS as a 'mongrel' concept. His main claim is that there are at least two importantly different concepts of 'consciousness', 'P-consciousness' and 'A-consciousness', and that various theories in cognitive science purport to explain the former, but they only really explain the latter. However, it has also been argued that there are at least nine different concepts of consciousness (Hill 2009, Ch.1). And Irvine (2012,

\footnotetext{
${ }^{1}$ We follow the convention of using capitals to denote concepts. We will use the word in quotation marks to refer to the term corresponding to the concept in question, so SPECIES should be taken to mean the species concept, whilst 'species' is taken to be the term corresponding to this concept, used in debates in biology and philosophy of science about species.

${ }^{2}$ For an entry to this vast literature see, e.g., Taylor 2000, Andreasen 2000, Hardimon 2003, and Glasgow 2003.
} 
Ch.6) argues that the concept CONSCIOUSNESS refers to several importantly distinct kinds of entity, and fails to pick out a natural kind (see also Rey 2010).

6. ATTENTION. In the debates within psychology over the nature of attention we find some thinkers (Styles 1997; Duncan 2006) suggesting that the concept be understood as a Wittgensteinian family resemblance concept which can be defined in several ways, no one definition being privileged. The same basic point has recently been made in the philosophical literature by Taylor (2015a). We also find pluralism about attention based not merely upon the fact that there are several different attention concepts, but also based upon the claim that 'attention' refers to several importantly distinct processes in the brain (Allport 1993). This line of thinking brings some to claim that attention does not exist (Anderson 2011).

7. HEALTH. Over many decades - even centuries - various different definitions of 'health' have competed. Blaxter (2004, Ch.1) mentions (among many other options) health as absence of illness, health as deviance from normality, and health as some kind of functional or homeostatic property of an organism. Indeed, even within each of these general approaches to the question 'what is health?' we find a plethora of different available definitions of 'health'. It is increasingly common in the literature to see writers advocate pluralism, often on the grounds that some of these definitions of 'health' will fulfil certain theoretical roles, and others will fulfil others. DISEASE and ILLNESS are also strong candidates for pluralism (see e.g. Hesslow 1993).

8. MEMORY. Psychologists today typically make distinctions between a great many different subvarieties of 'memory' such as working memory, short term memory, iconic memory, and long term memory (see e.g. Baddeley et al. 2009). These 'kinds of memory' operate in importantly different ways, making use of different systems in the brain. And within these categories further subdivisions are routinely made (e.g. between 'declarative' and 'non-declarative' long term memory). This taxonomy of memory is an ongoing project: recently the concept of 'iconic memory' has bifurcated into 'pure' iconic memory and 'fragile visual short term memory' (e.g. Sligte et al. 2008, 2009).

9. SCIENTIFIC EXPLANATION. Throughout the 20th century and right through to the present day there has been a major debate concerning the nature of 'scientific explanation'. At least five major theories have been put forward (see e.g. Woodward 2014), and have generally been considered as competing theories. Today it is increasingly common to see a pluralist approach to scientific explanation. For example, Plutynski (2004, p.1205) writes, "Philosophers of science have, I think, been mistaken in seeking out the relation in virtue of which scientific explanations explain.” (p.1205). Cf. Woodward (2014), Section 7.3, entitled 'A Single Model of Explanation?'.

10. SCIENTIFIC METHOD. Attempts to articulate the scientific method are as old as philosophy of science itself, and 'scientific method' has been defined in umpteen different ways. It was long taken for granted, without question, that these different definitions competed with each other. Today, following the influence of

\footnotetext{
${ }^{3}$ Closely related to this view is the claim that ATTENTION is a cluster concept. Some thinkers distinguish between cluster concepts and family resemblance concepts, but nothing we have to say in this paper will turn upon this.
} 
Feyerabend and others, a pluralist approach is "current orthodoxy" (Sankey 2010, p.255).

These are ten fairly concrete examples (give or take). It is easy to list another ten examples which are more controversial, but where pluralism is a serious 'live' option in the literature:

11. CONCEPT - e.g. Machery $(2005,2009)$.

12. PROBABILITY - e.g. Carnap (1945); Percival (2000).

13. LIFE - e.g. Machery (2012); Mix (2015).

14. PHYSICALISM - e.g. Chalmers (2011, pp.533-534).

15. SCIENCE - e.g. Newton-Smith (2001, p.2).

16. CHEMICAL BOND- e.g. Hendry (2008).

17. INNATE - e.g. Griffiths (2002).

18. NATURAL KIND- e.g. Dupré (1993).

19. SCIENTIFIC THEORY (pluralism concerning the general concept) - e.g. Magnus (2012); Vickers $(2013,2014)$.

20. SCIENTIFIC THEORY (pluralism concerning individual theories) - e.g. Fletcher (2012), partly drawing on Malament (2008) and Wilson (2009); Vickers (2013, 2014).

For each of the listed concepts one can form that staple question of philosophy 'What is $\mathrm{x}$ ?', where $\mathrm{x}$ stands for 'memory', 'intelligence', 'a concept', and so on. And in each case the (short) answer - for many people at least - is: ' $\mathrm{x}$ is many things', whereas at one time there was fierce debate concerning the one right answer to the question 'What is $\mathrm{x}$ ?'.

We will use the term 'conceptual fragmentation' to refer to any case where: (i) a certain term, originally widely assumed to enjoy a single meaning, has been found to have multiple distinct meanings no one of which is privileged, and (ii) different definitions are adopted for different theoretical uses. ${ }^{5}$ This is intended to cover cases where the term is ambiguous, as well as cases where the term refers to a variety of different kinds of entity. As we shall see, when conceptual fragmentation does occur there are a variety of different reactions one might have. One might, for example, accept that a certain term has multiple different possible meanings, no one of which is privileged, but insist that we should continue to use the original term in our investigations. Alternatively - as seen within the list of examples given above - sometimes thinkers take conceptual fragmentation as justification for retaining the different individual meanings whilst eliminating the original term that has been subject to

\footnotetext{
${ }^{4}$ And the list could certainly be extended. Another interesting possible candidate is ENTROPY. As Maroney (2007) states: "The literature abounds with alternative definitions of entropy" and Capek and Sheehan (2005), Ch.1, Section 1.3 is entitled: 'Entropy: Twenty-One Varieties'. There are also many examples beyond (philosophy of) science, including: PERSONAL IDENTITY (see e.g. Shoemaker 2007), LOGIC (Beall and Restall 2006), BELIEF (see e.g. Needham 1972, p.131), MUSIC (Currie and Killin, forthcoming) and ART (Uidhir and Magnus 2011). Chalmers (2011, p.540) even goes as far as to write: "I am inclined to think that pluralism should be the default view for most philosophical expressions."

${ }^{5}$ It should be clear that mere homonyms are ruled out by condition (i).
} 
fragmentation. We introduce the term 'conceptual fragmentation' to capture what is common to these positions. ${ }^{6}$

The given list of examples can form the basis of a crude inductive argument for the claim that we should expect cases of fragmentation to proliferate in the future. Given the wide range of very different concepts on the list, the question naturally arises for a crucial concept in any other scientific debate, 'Why wouldn't this other concept also be susceptible to the same kind of pluralistic treatment?' We think that this inductive argument is reasonable support for the claim that we can expect conceptual fragmentation to proliferate in the coming years in a great many more debates. However, we also believe that we can do better than this, by identifying an underlying process which gives rise to conceptual fragmentation. We turn to these issues in section 2. This will lead us on to an argument for the claim that conceptual fragmentation will occur (or ought to occur) with great frequency in many debates within science/philosophy of science. Important ingredients in this argument are: (i) the death of the classical theory of concepts (and related facts concerning the development of language, concepts, and meanings), (ii) the relentless increase in the (range of) phenomena to be explained within any given scientific field over time, and, closely related to this, (iii) the multiplication of scientific aims, interests, questions, and pursuits over time. ${ }^{7}$

In Section 3 we ask the question under what circumstances conceptual fragmentation warrants an eliminativist approach to the term/concept in question, and two heuristics are put forward. These heuristics dictate that the case for eliminativism depends not only on the term in question, but also the context of debate. Eliminativism is thus selective, and this in turn provides a means for dissolving many of the debates in the literature between 'pluralists' and 'eliminativists'. In Section 4 we turn to two objections and replies; Section 5 is the conclusion.

\section{The road to conceptual fragmentation}

In this section we offer an explanation as to why cases of conceptual fragmentation are on the rise within (philosophy of) science. We outline a three-step process which is sufficient for conceptual fragmentation. ${ }^{8}$

We start by noting that archetypally, within both science and philosophy, questions often take the form 'What is $x$ ?', where ' $\mathrm{x}$ ' is a particular term we are interested in; examples include 'What is knowledge?', 'What is science?', 'What is life?', and 'What is memory?' When answers are given to such questions, their worth obviously has to be

\footnotetext{
${ }^{6}$ It is important to note that (ontological) eliminativism of the kind proposed by Churchland (1981) is not the focus of this paper.

7 The terms 'aims', 'interests', 'questions', and 'pursuits' should each be interpreted in quite a fine-grained way: two examples of 'aims' would not be explanation and prediction, but rather two different sorts of explanation, or perhaps the explanation of two different kinds of phenomena.

${ }^{8}$ It is important to note that we do not consider this three-step process necessary. In particular, we do not consider the death of the classical theory of concepts necessary. If we did, Carnap (for example) would (probably) constitute a counterexample to our view, given his definitionism and his pluralist take on PROBABILITY. More on Carnap below.
} 
judged. One particularly prominent criterion for judging such answers is what we shall call the 'extensional adequacy criterion' (EAC):

Any answer to the question 'What is $\mathrm{x}$ ?' should not exclude any cases which certainly are $\mathrm{x}$, and not include any cases which certainly are not $\mathrm{x}$.

The basic idea behind the EAC is that if one aims to say what $x$ is, then one's view should not be subject to counterexamples. A great number of debates in both science and philosophy of science have an account-counterexample structure, and are guided by the EAC. We believe there is good reason to think that these debates often give rise sooner or later - to conceptual fragmentation and also to pluralist and eliminativist positions. Our reasons for thinking this are linked to the death of a particularly prominent theory of concepts within cognitive science and the philosophy of concepts: the definitional view/'classical' theory.

It was at one point a popular view that the content of our concepts derives from definitions: we understand the concept BACHELOR from associating with it a certain set of necessary and sufficient conditions, something like being a man and being unmarried. On this view, being an unmarried man is necessary and sufficient to be a bachelor, and this is how we understand what the concept BACHELOR means. For this view, (non-primitive) concepts get their content from having definitions. ${ }^{9}$

It is safe to say that this definitional view is now largely ${ }^{10}$ dead within both cognitive psychology and the philosophy of concepts. It will be helpful to quote Fodor on the matter:

[T]hese days almost nobody thinks that concepts are definitions... There are practically no defensible examples of definitions; for all the examples we've got, practically all words (/concepts) are undefinable. (Fodor 1998, pp.44-45)

Since 1998 the view that concepts cannot be defined has only gained wider acceptance (cf. Machery 2009, p.80ff). Several factors contributed to the death of definitionism, one of the most prominent being (as Fodor notes) that there seem to be no uncontroversial examples of definitions of any concept whatsoever. Any proposed definition was either circular, or subject to counterexamples. For example, it was often said that BACHELOR cannot have the content UNMARRIED MAN, as that would count the Pope as a bachelor. Attempts to revise the definition of the concept BACHELOR have met with similar criticism. Indeed, as Fodor (1981) has argued, even supposedly simple concepts such as 'paint' (taken as a transitive verb) resist definitions. ${ }^{11}$

In the wake of the death of definitionism many new theories of concepts have gained prominence. Whilst each of these theories remains controversial in its own ways, all are unanimous in the rejection of the claim that concepts in general can be defined. Now, if we take seriously the death of definitionism, then it gives us a way to explain why there

\footnotetext{
${ }^{9}$ The classical theory of concepts has a very long history, although of course it wasn't always an explicitly held position. See Margolis and Laurence (1999) for discussion, where definitionism vis-à-vis concepts is associated with Plato (see Chapter 2) and Locke (see p.9) among others.

${ }^{10}$ Jackendoff (1992) holds a significantly modified and restricted version of the view.

${ }^{11}$ Stipulative definitions do not present such a problem, of course. Indeed, stipulative definitions play an important role in our following arguments.
} 
are so many different proposed definitions of any given term no one of which is privileged above the others. Take any particular scientific term philosophers are interested in. Any attempt to define that term will fail in one way or another. As each definition fails, new definitions are put forward. We end up with several definitions all of which fail to be 'perfect'.

This is the first step on this particular road to conceptual fragmentation, but it is not sufficient. If the community are all definitionists, then although there are various definitions in the literature, nobody will care about the ones which face counterexamples except perhaps to see if they can be modified in the search for the 'correct' definition. For conceptual fragmentation (as we have defined it) the community needs to come to believe that some (several) of the definitions put forward for a given concept are important and valuable just as they are. The process by which the relevant definitions become accepted by the community can be separated into two smaller steps: (i) coming to judge definitions not by their extensional adequacy, but instead by whether they are theoretically useful, and (ii) finding that more than one definition of a given term/concept is theoretically useful. ${ }^{12}$

Thinking about (i) to start with, one might ask the question why we should expect any of the definitions put forward in the spirit of definitionism to be theoretically useful. One of the main reasons, we submit, is that when a definition is put forward it is usually put forward along with a use. For example, consider the long-standing debate concerning what is it for something to count as a scientific explanation. The 'deductive-nomological' (DN) account tells us that an explanation consists in a deduction which involves at least one law of nature. The flagpole-shadow case is a famous counterexample: the length of a flagpole's shadow does not feature in an explanation of the length of the flagpole, as this account suggests. So, when the causal account of scientific explanation was put forward it was stressed that this new account makes perfect sense of this example: the length of the pole causally affects the length of the shadow, but the length of the shadow does not causally affect the length of the pole. Now, some people wonder whether the causal account itself has serious problems and/ or counterexamples. ${ }^{13}$ But most would agree that, even if it does, it still does a good job of explaining what is going on in the flagpole-shadow case, and also in many other cases. Definitions of 'health', 'illness', and 'disease' are other obvious examples. Within 'disfunction' theories of disease, Wright (1973) provides a definition to avoid counterexamples aimed at Boorse (see Cooper 2002). This new definition can remain useful for understanding the cases it was designed to explain, even if it cannot work as a global theory of disease. ${ }^{14}$ Similarly, phenomenological accounts of disease can be useful for understanding certain cases where naturalistic accounts have trouble, even if phenomenological accounts also fall short in certain contexts (e.g. anorexia nervosa see Carel 2008, Ch.1).

Finally, consider SCIENTIFIC METHOD. Three of the major theories put forward in the 20th century are the hypothetico-deductive (HD) method, Popperian

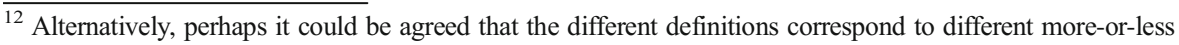
'natural' kinds in the world: what we originally thought was a single type of thing is actually a multitude of different kinds of thing. But see Section 4(i), below.

${ }^{13}$ For an entry to the literature on non-causal explanation see e.g. Skow (2014).

${ }^{14}$ Disfunction does not appear to be sufficient for disease, if we consider people taking contraceptive pills, to give one example.
} 
falsificationism, and a Kuhnian method largely based on 'normal science' problem solving. As each one of these was put forward and defended, concrete scientific episodes from the history of science were put forward as evidence of the applicability and usefulness of the theory. Critics would then put forward other concrete examples which posed problems. Following the influence of Kuhn, Feyerabend, and others (cf. Sankey 2000), in the end (nearly) everybody agreed that, actually, many different theories can all be 'good' in the sense that science works in different ways, and we should not expect a single theory of the scientific method which can accommodate all possible cases. The concrete cases put forward to support each account remain cases helpfully explicated within the terms of that account, even after it becomes accepted that it cannot possibly stand as a general theory of the 'one, true scientific method'. Of course, some accounts/definitions will (intuitively) have fewer counterexamples (or more applications) than others. But a definition with many counterexamples (and few applications) might nevertheless be useful and important for a certain cluster of cases.

In summary, this is what we believe contributes to conceptual fragmentation in a great many cases: we start with attempts to give necessary and sufficient conditions for the concept in question. This leads to a collection of different proposed definitions. None of the definitions can give a 'perfect' account of the content of the original concept (since concepts cannot be defined in this way) but several of the proposed definitions will be useful in a variety of different contexts, and this is what justifies their preservation. Crucially, the 'death of definitionism' refers to the rejection of the claim that the content of concepts can be captured by (non-circular, reductive) definitions. It does not imply that definitions should play no role in our philosophical (and scientific) debates. On the contrary, we claim that there is an important role for stipulative definitions which fail to capture the content of the original concept, but which succeed in the sense that they are contextually useful for shedding light on certain questions. Often definitions originally put forward in the spirit of fulfilling the EAC simply need to be reconceived as stipulative definitions.

A response is possible here. If a person does not actually believe in the death of definitionism, then she may well keep on searching for the one true definition/theory of $\mathrm{X}$. Such a person would not be motivated to 'keep' proposed definitions which face insurmountable counterexamples, because she will not accept our premise that any definition will always face counterexamples. If everyone in the community thinks in this way, then an interesting fragmentation of the sort sketched above will not get a foothold. It might be true that no definition can ever be 'right', and also true that various definitions already in the literature can be useful in different contexts, but we do not yet have conceptual fragmentation (in the sense intended) if every individual is still searching for the one, true definition or theory.

One reason that conceptual fragmentation is taking hold is simply that the death of definitionism is becoming more widely known and appreciated, and philosophers are increasingly acting accordingly. ${ }^{15}$ This entails accepting that every definition will face counterexamples; however, many philosophers still like to work with definitions, albeit emphasising the usefulness of a given definition as a reason to introduce it, even if it is

\footnotetext{
$\overline{{ }^{15} \text { Griffiths (1997, 2002), Machery }}(2009,2012)$, Magnus (2012) and Uidhir and Magnus (2011) are clear examples of this phenomenon.
} 
not extensionally adequate. To put it another way, definitions are increasingly put forward in the spirit of pragmatism ("This definition will be useful in the following ways...") as opposed to in the spirit of definitionism ("The necessary and sufficient conditions for $X$ are..."). Of course, not everyone in a given debate will make the transition to pragmatism, and sometimes we find rather blurred lines between those in a debate searching for 'correct' definitions and those in a debate searching for (merely) useful definitions. But the increasing emphasis on pragmatist thinking when it comes to definitions is (i) to be expected given the (relatively recent) death of definitionism, and (ii) evident in the literature.

This emphasis on pragmatist thinking is to be found throughout the literature, and it would not do to document too much of it here given space constraints. But we can mention a few examples just to give a sense of how things are shifting. Consider Wu (2011) as he attempts to motivate his definition of 'attention':

My goal is to identify a theoretical conception that is psychologically and philosophically useful. (p.97)

Consider also Percival (2000) when discussing the concept 'probability':

[I]n my view one should not require the results of a conceptual investigation into the nature of probability to coincide exactly with what agents mean by "the probability of such and such." The really important issue is what agents might profitably mean by it. (p.360)

Similarly, when discussing 'scientific theory', Belot (2007) makes a similar point: "[I]n choosing a sense for the term 'theory' in philosophy of science, we have a trade off between fidelity to common use and fecundity of the explicans." In other words, for any suggested definition of 'theory', we ought to be considering the ways in which that definition can do philosophical work for us, not just whether the definition matches people's intuitions.

Notice that in these examples we have an emphasis on use, but we do not yet have a plurality of uses. That is to say, we still need the final step in the process: it needs to be the case that several definitions are theoretically useful, not merely one. A philosopher might be pragmatically minded, but simply want to find the one, best definition which is most useful, or which covers all possible uses one might be interested in. However, once one has taken the step to judge definitions on whether they can be useful (as opposed to extensionally adequate), fragmentation is quick to follow. The fact is that, in practice, one just does find that more than one definition of a given term will be useful, depending on the context, the debate in which it appears, the interests, values, and goals of the enquirers, and so on. Often this stems from the fact that the participants in the debate have different interests, and are engaged in different projects, and as a result end up putting the same term to different uses.

For example, consider the recent debate concerning whether classical mechanics is a deterministic theory. Fletcher (2012) writes as follows: "there are many different conceptions of classical mechanics appropriate and useful for different purposes" (p.275). He continues: "In practice, the choice of a particular formulation of classical mechanics will depend largely on pragmatic factors like what one is trying to do with 
the theory" (p.277). Thus he argues that there is no fact of the matter as to whether classical mechanics is a deterministic theory - it depends on how one formulates the theory, and there is no one 'correct' or 'best' formulation of the theory. Another helpful example concerns the definition of 'species'. Here it is clear that different available definitions are suited to different theoretical purposes (see e.g. Ereshefsky 2010a, b). One particularly striking example is the difference between the phylogenetic species concept (that taxonomises organisms into species in virtue of them sharing common descent - e.g. Hennig 1966) and the interbreeding one (which taxonomises organisms based upon their being interbreeding groups that produce fertile offspring - e.g. Mayr 1970). Each of these two prominent understandings of 'species' is suited to different theoretical purposes. For example, certain species of organisms that do not interbreed at all (i.e. they reproduce asexually) are obviously unsuited to being investigated in terms of the interbreeding understanding of 'species'. However, in spite of this, interbreeding has been an important motivating force behind the evolution of a great many organisms on the planet and has produced stable taxonomic units of interbreeding organisms. So, our evolutionary biology would be impoverished if we neglected the importance of the interbreeding species concept in relation to these organisms (see Ereshefsky 1992a, b, 1998).

It is not difficult to find further concepts that have been burdened with a wide plethora of theoretical uses. LIFE is a good example. As Machery (2012) notes, the term 'life' has been put to work in evolutionary biology, molecular biology, the study of the origins of life, synthetic biology, artificial intelligence research, research into the possibility of finding life on other planets as well as research in ethics, relating to questions such as the ethics of abortion and environmental philosophy. As Machery goes on to note, each of these disciplines has its own interests and methodologies. To quote just one of his examples:

The evolutionary definition of life... may be attractive in synthetic biology, since, in a lab, scientists can observe whether artificial products are capable of evolving. It is much less attractive in astrobiology, for in situ search for life spans over periods of time that are too short for finding evidence of evolution. (2012, p.158)

Of course, within the abortion debate one would expect the appropriate definition of 'life' to be once again different.

As another example consider the amount of work the word 'theory' has been put to in philosophy of science. Just to give a flavour, there are (i) debates concerning intertheory relations, (ii) debates concerning the interpretations of theories, including their metaphysical commitments, (iii) debates concerning the properties of theories, including whether they are consistent, deterministic, time-reversal-invariant, and so on, (iv) debates concerning theoretical virtues in theory choice, (v) debates concerning the relationship between theories and 'models' (for various interpretations of 'model'), and (vi) debates concerning whether theories are true, approximately true, mere instruments, or otherwise. We also have a vast number of different 'theories of theory' in the philosophical literature. No surprise that some of these accounts are suited to some of the uses to which the term 'theory' has been put, and other accounts are suited to other uses. For example, Muller's (2011) preferred account of a theory as a 'set of structures in the domain of discourse of axiomatic set-theory, characterised by a set-theoretical predicate' might be extremely useful for revealing whether or not there is an 
isomorphism relation between Schrödinger's wave mechanics and Heisenberg's matrix mechanics (Muller 1997). But a highly abstract, formal account such as this is hardly suited to understanding the sense in which Darwin had a theory concerning the evolution of species, or the sense in which Bohr had a theory of the atom.

Summing up, this section has described a process leading from monism to fragmentation. The first link in the chain is the death of definitionism, which has the result that no one proposed definition of a concept can be 'correct', which in turn leads to more than one definition being put forward. The second link in the chain is the fact that proposed definitions become judged by their theoretical usefulness. The final link is that several of the proposed definitions prove to be theoretically useful, applicable in different contexts. ${ }^{16}$ The upshot is this: if one wishes to remain a monist about a given concept, one needs to have a story to tell concerning where this chain is broken for that particular concept. ${ }^{17}$

Perhaps monists will want to challenge the idea that, for a given concept, there will typically be a large number of theoretical uses the concept is expected to fulfil. There are many concepts, after all, which are not expected to fulfil a number of different theoretical uses, including BOILED EGG. But are there any/many examples within science? If we think again about the third link in the chain, the claim is that different definitions will be useful for different purposes. Why should we expect that of scientific terms? Why shouldn't one definition do all of the work? The reason (we submit) is that expressions get introduced into a field at a time when only a small fraction of the interesting phenomena have been identified. As any field develops the phenomena to be explained multiply. Very rarely can all the new phenomena be considered of exactly the same kind. Usually there will be new phenomena of the same kind, new phenomena of quite a different kind and (significantly for us) new phenomena which are somehow in-between, such that they are closely related to old phenomena, and yet subtly but significantly different. The new phenomena demand explanation, and the terms which have already been involved in successful explanations are invoked again for the new, related phenomena (especially the very closely related phenomena). ${ }^{18}$ Thus one and the

\footnotetext{
${ }^{16}$ We talk of several different proposed definitions, rather than several different definitions. The word 'proposed' is included to emphasise that although the definers might think they have the definition of the concept in question, we should be sceptical of the idea that there really is one concept that all of the different definitions are trying to capture. Indeed, in our view only rarely will it make sense to say that two different definitions correspond to one and the same exact concept. Instead each definition has its own corresponding concept (or even concepts). So nothing we say should be interpreted as claiming that there are several different definitions of one and the same concept. When we talk about various different definitions of a concept what we really mean to refer to are the various different definitions of a single term (which is often assumed by the definer to correspond to only one concept, the concept their favoured definition picks out).

${ }^{17}$ Carnap presents an interesting case, since he was a pluralist long before the death of definitionism. If there were a great many others like Carnap in the history of philosophy, for all different concepts, then perhaps there would not be a 'rise of pluralism' to explain, nor would the death of definitionism be as significant as we claim vis-à-vis fragmentation. However, each of our twenty examples other than PROBABILITY is relatively recent. And even PROBABILITY is not a clear counterexample when one considers that, for us, fragmentation is not just about finding a single philosopher who takes a pluralist approach to some concept; it's about a wider trend of thought vis-à-vis that concept. When it comes to PROBABILITY Carnap was ahead of the game, writing in 1945: "When every author has not only a clear understanding of his own explicandum but also some insight into the existence, the importance, and the meaning of the explicandum on the other side, then it will be possible for each side to concentrate entirely on the positive task of constructing an explication and a theory without wasting energy in futile polemics against the explicandum of the other side." (Carnap 1945, p.531 f.). 18 This sort of phenomenon is well known in the linguistics literature. See below.
} 
same term becomes involved in numerous different explanations. In this way we have the multiplicity of purposes, and a multiplicity of concepts follows closely behind. ${ }^{19}$

In opposition to the monist, we should ask the following question: what would be the motivation for trying to make do with a single definition of a concept? This question is especially pressing given the death of definitionism; the motivation cannot be that one definition will be 'correct'. Nor is it plausible that one definition will be 'best' or 'the most useful' for all purposes and in all contexts. The burden of proof is surely shifted here.

\section{Pluralism, eliminativism, and the best of both worlds}

So far we have mainly referred to 'fragmentation' as opposed to 'pluralism' or 'eliminativism' specifically. Our idea in the previous sections was to stay neutral insofar as this is possible - between pluralist and eliminativist positions. 'Fragmentation', as we have used it, refers to any situation where a term enjoys multiple different definitions, no one of which is privileged and several of which are deemed valuable. Pluralists and eliminativists can agree to this development, but then eliminativists want to go one step further and 'get rid of' or 'do without' the original term. ${ }^{20}$ There are, of course, different ways to be a pluralist or eliminativist. Pluralists typically agree that the term in question should be retained, but may differ between (i) conducting debates 'business as usual', and (ii) conducting debates in an adjusted way, such that the term in question is not put to any theoretical work. Eliminativists insist on a greater adjustment to the status quo, but can differ between (iii) replacing the term with modified versions of the term (e.g. 'species' becomes 'biospecies', 'ecospecies', etc.), and (iv) completely eliminating the term. ${ }^{21}$

In our view the most important issue concerns when it is appropriate to eliminate a term, since eliminating a term - whether opting for option (iii) or (iv) - is the most dramatic suggestion. Eliminativism has a reputation for being an altogether too radical proposal. However, it is nearly always viewed as an all-or-nothing option for a given term. An important alternative is to adopt a selective eliminativist position, where a term should be eliminated in some contexts but not others. This allows us to enjoy all the advantages of eliminativism whilst making it a much more defensible proposal. We identify two heuristics for deciding when to eliminate:

(a) Other things being equal, the greater the number of theoretical roles that a certain term is put to, the greater the warrant for eliminating that term, the reason being that the term is very likely to take on different (perhaps very subtly different)

\footnotetext{
${ }^{19}$ It is perhaps worth emphasising that there is nothing intrinsic to the concept BOILED EGG that prevents it from fragmenting. If there were some set of debates which put theoretical weight on the concept BOILED EGG, and expected the concept to explain various different phenomena, then we would indeed expect the concept to fragment.

${ }^{20}$ Here we restrict ourselves to discussing eliminativism about terms rather than ontological eliminativism to the effect that a certain set of entities do not exist; cf. Churchland 1981. We will, however, say something about ontological considerations in Section 4.

${ }^{21}$ An instance of option (i) is Weiskopf (2009) on 'concept' (cf. Prinz 2010); an instance of option (ii) is Ereshefsky (2010b) on 'species'; an instance of option (iii) is Ereshefsky (1998) on 'species'; an instance of option (iv) is Machery (2009) on 'concept'.
} 
meanings in each of (or at least many of) the different theoretical roles, and this increases the chance of people talking past one another when deploying that term.

(b) Other things being equal, the more pivotal the role a concept plays in the arguments put forward to reach one's conclusions, the greater the warrant for eliminativism. If your argument hangs (very heavily) on what you mean by ' $\mathrm{x}$ ', then it is safer to tell people how you are using ' $x$ ', and it is even better to eliminate ' $x$ ' altogether. (See below for a concrete example concerning the inconsistency of 'classical electrodynamics'.) An important special case here (cf. Chalmers 2011, pp.531-2) concerns debates centred on the question 'What is $\mathrm{x}$ ?', or related questions such as when one asks whether $\mathrm{y}$ 'counts as' an $\mathrm{x}-$ questions such as 'Is Pluto a planet?'22

In some cases of fragmentation eliminativism need not be embraced, whereas in other cases it should be. Heuristics (a)-(b) are in place to determine when we have warrant to eliminate a term that corresponds to a fragmented concept. The greater the extent to which a case satisfies (a), (b), or both, the greater the warrant to eliminate the term in question, replacing it with a more fine-grained taxonomy. The reason these heuristics are good indicators of when we should eliminate a particular term is that they both defeasibly track situations where verbal disputes and bad questions can arise over certain crucial terms in the debate. Eliminating the term in question would make this kind of verbal dispute impossible: by removing the term from the debate, it becomes impossible for different interlocutors to misunderstand each other's use of the term. The debate is then transformed accordingly. ${ }^{23}$

Notice that heuristics (a)-(b) make reference not just to the nature of the term itself, but also to factors external to the term, such as the number of theoretical roles that it is put to, and how pivotal its argumentative role is. In other words, heuristics (a)-(b) essentially make reference to the context in which a term is deployed. In order to assess whether a term fulfils heuristics (a)-(b), one must examine this context. One cannot decide whether they are met by examining the term in isolation from how it is actually deployed.

We should at this point say something about what a 'context' is. We take a term's 'context' to be determined by several factors, including the particular set of debates the term features in, the sum of the theoretical roles that the interlocutors in these debates expect the term to fulfil, as well as other facts about the term, such as how aware of the term's alternative meanings the practitioners in the debate are, and how likely they are to confuse one meaning for another. In this way, a particular term's theoretical context will be partially determined by the mental states of the practitioners in the debate (such as their awareness of certain distinctions) but it will not be entirely a matter of interpretation what the context is: it is not up to each individual interlocutor what roles a particular term has been expected to fulfil, whether mistakes over the different

\footnotetext{
${ }^{22}$ Cf. Sidelle (2007), who introduces the Pluto question in his discussion of 'verbal disputes'.

${ }^{23}$ Of course, for a term to fulfil heuristics (a)-(b), it is not enough that it is simply used a great deal in a particular context. For example, the term 'geometry' has been used in a wide variety of different ways and (arguably) the concept is fragmented. However, because the term does not figure in any of the actual claims of mathematics (at least, not in formal work) it does not fulfil many theoretical roles (thus not fulfilling (a)) and it does not play a pivotal role in mathematics (thus not fulfilling (b)). So in the case of 'geometry', we need not move to eliminativism, even though it is a widely used and prominent concept in mathematics.
} 
meanings of the term in question are likely to arise, or whether they will be devastating for the debates in question.

With these clarifications in place, it will be instructive to see how heuristics (a)-(b) apply to a concrete case. Consider the debate as to whether the theory of classical electrodynamics is inconsistent. Frisch (2005) argues that it is inconsistent, but Belot (2007) and others disagree. Vickers (2014) argues that Frisch and Belot have conceptions of 'classical electrodynamics' which overlap a great deal, so that in practice what they both take the content of the theory to be is almost exactly the same. However, the small differences mean that for Belot the theory is consistent, but for Frisch the theory is inconsistent. Thus we get a very significant difference arising from a very small difference in the meaning of 'classical electrodynamics'.

Eliminativism vis-à-vis 'classical electrodynamics' is worth taking seriously here, since in this case heuristics (a) and (b) both come into play. Confidence that professional philosophers can handle such situations without bothering to eliminate is further undermined when we notice that miscommunication can happen even when the author provides a definition to tell the reader how a key term is being used. Frisch is sensitive to the fact that he needs to cash out his key terms, and accordingly he explains how he is using the word 'theory': "Throughout my discussion I will refer to the scheme used to model classical particle-field phenomena as a "theory'." (Frisch 2005, p.26). But his work still leads to an unfortunate verbal dispute with other philosophers of physics who claim that Frisch is wrong to think that 'classical electrodynamics' is inconsistent. The problem here is that philosophers sometimes have very fixed views on what a word can be taken to mean, such that either (i) they misinterpret the definition that is given, or (ii) they simply think the definition is wrong, so that any discussion based on that definition is at best misleading.

This is just one example, to illustrate the basic idea. The debate would have been much more effective if 'classical electrodynamics' had been eliminated, and claims stated in alternative ways. ${ }^{24}$ And this is a situation where the philosopher making the claim actually was quite careful, stating explicitly how the term in question was to be understood. In general terms, the thing about this debate is that an abstract term plays a pivotal role in the arguments put forward: a very small difference in the meaning of that term leads to a very significant difference in conclusion. One might have expected the term 'classical electrodynamics' to be precisely defined, but even established scientific theories have issues concerning the interpretation of key terms and equations - we have already mentioned similar issues concerning classical mechanics. Cases such as this show that however confident one is that one can just 'be careful', without bothering to eliminate, one is always taking a risk if one does not eliminate. The thing about 'care' is that it is (very!) fallible. Eliminativism, by contrast, is fool-proof when it comes to avoiding these worries: it is impossible to talk past one another regarding term ' $\mathrm{x}$ ', or to have a verbal dispute about ' $x$ ', if ' $x$ ' has been eliminated. The smaller the difference between two different concepts, the less likely the interlocutors in the community are to notice the differences between them, and thus the greater the risk of miscommunication.

This leads us on to another important point: many readers at this point might be sceptical that eliminativism will be required in very many contexts. Such readers may

\footnotetext{
${ }^{24}$ As Frisch himself reflected in 2008: "I am inclined to agree with my critics that this inconsistency in itself is less telling than my previous discussions may have suggested." (Frisch 2008, p.94).
} 
simply have confidence that professional philosophers know how to handle concepts, and can use them appropriately, such that (i) the context of discussion will tell the reader how a term is being used, or (ii) if the context is not sufficient, the author will recognise this and provide a definition. Such a reader will then conclude that, given these facts about professional philosophers, eliminativism will be appropriate only in very rare circumstances.

We feel this is overly optimistic: one must take note of the fact that there simply are many examples of philosophers talking past one another, miscommunicating, and having verbal disputes when they think they are having disputes of substance (e.g. the Frisch debate just discussed). However, this raises a question: if philosophers are professional concept-handlers, then why do these difficulties arise with such frequency in philosophical debate? We believe that one of the main contributing factors to this frequency has to do with situations where two participants are using the same word in ways that are only very slightly different, such that it is very difficult to detect the difference in meaning, but the consequences of this difference for the debate in question are very great.

Such situations crop up in language absolutely everywhere. Indeed, a large part of linguistics is devoted to understanding just this sort of phenomenon, understood under headings such as 'concept broadening', 'concept narrowing', 'category extension', 'polysemy', and 'contextual meaning'. ${ }^{25}$ Naturally linguists disagree on matters of theory, but all agree (more or less) on the phenomena to be explained. The fact is, we use the same terms in a very wide variety of different ways, and meanings are being 'bent' all the time.

It is quite common for the same term to be used in significantly different ways within a community, and the linguistics literature is crammed with concrete examples. But it is even more common for the same term to be used in very subtly different ways. Naturally if the differences are small enough it will be common for people to not even notice they are using the term in slightly different ways. But why should that matter? Why would very small differences in meaning have very significant consequences? If the reader is a philosopher, we should not really have to answer this question! Philosophy is all about subtle differences making all the difference (and the electrodynamics example is a clear case).

At this point, an opponent may suggest a rival to selective eliminativism, which we might call 'selective stipulativism'. ${ }^{26}$ On this view, when a concept fragments and the corresponding term fulfils heuristics (a)-(b), we should simply stipulate definitions for the term as appropriate to the context of use. In this way we make explicit via the different stipulative definitions the small changes in meaning between different interlocutors' use of a term, thus avoiding many of the problems associated with subtle differences as outlined above. However, again we feel that this is overly optimistic. First, there are clear examples (such as the Frisch case) where an interlocutor clearly defines a term, and yet its use is still misunderstood by other thinkers in the debate. Retaining a term, even if one is clear about the intended definition, will always run the

\footnotetext{
${ }^{25}$ For an entry to this vast literature - highly relevant to philosophy but often overlooked - see for example Clark and Gerrig (1983), Murphy (1997), Lasersohn (1999), Carston (2002), Fauconnier and Turner (2002), and Wilson and Carston (2007). Wilson and Carston (2007) go as far as to claim that "there is no principled limit on the possible interpretations of words in use (i.e. given that there are indefinitely many possible contexts, there are indefinitely many possible adjustments of the encoded sense(s))."

26 Thanks to an anonymous referee for suggesting this to us.
} 
risk of other thinkers importing their own assumptions concerning how the term should be understood. Second, the term in question will typically have several different theoretical roles, for which different stipulative definitions would be required. But then we would have a situation where a single term is still used, but has several (perhaps many) alternative definitions associated with it. In such a situation, any use of the term without the intended stipulative definition would likely give rise to confusion and crosspurpose talking. Furthermore, any use of the term with the intended stipulative definition would make the term redundant - one might as well be an eliminativist. In our view selective stipulativism has no advantages over selective eliminativism, and additional disadvantages.

Our conclusion is that the status quo is not desirable at all, and neither is the alternative 'selective stipulativism'. It is already clear that 'taking care' or stating definitions openly is not enough, given that the literature is littered with examples of the sort of miscommunication we are worried about. But in addition the above considerations tell us just why we waste our time with verbal disputes so often. The key ingredients which cause verbal disputes (and which we have indicated in heuristics (a) and (b)) come together so often. It comes down to a simple choice in the end: take a risk, or don't take a risk. Because if one eliminates a term which (perhaps) did not really need eliminating, that will not negatively affect the debate in any significant way; it just means one has been overly cautious. It does mean that certain questions can no longer be asked. But if these questions depend on using a word which has several different meanings, then they are questions we can usefully replace with new questions which bring out the different senses of the term. ${ }^{27}$

We have illustrated some of the advantages that selective eliminativism has, when a term fulfils heuristics (a)-(b). Compared to the advantages of this approach, there are very few drawbacks to selective eliminativism, and none of them are serious. It may be said that selective eliminativism wastes time and effort, because it forces thinkers to come up with an account of how they are using the term in question (which will often be an intricate and subtle process) and then repeatedly use a longer phrase rather than the original term. However, we claim that eliminativism will save far more time and effort than it costs, by sidestepping pointless disputes. Furthermore, analysing the theoretical work that one expects a particular term to fulfil is work that should be carried out by the thinkers anyway, whether or not they are eliminativists, so the extra time and effort that selective eliminativism forces is no bad thing. An opponent may also say that by banning certain terms, the overall expressive power of the theory is reduced. However, given that the term in question can be replaced with any combination of other terms, we do not think that this loss of expressive power will be significant. Furthermore, in cases where eliminativism is applied, many of the claims that we will lose the ability to express are claims that should be avoided anyway, because they contain terms that are ambiguous and misleading.

These considerations convince us that eliminativism should be embraced far more widely. It is also crucial, in our view, that eliminativism be selective in the sense that its

\footnotetext{
${ }^{27}$ Vickers (2014, Section 4) argues that anything that is important to say can still be said if one eliminates 'theory' from philosophy of science: "[T]he questions which really matter can still be asked and answered." (p.111). Taylor (2015b, ch.5) argues similarly in the context of eliminativism vis-à-vis the term 'attention' in debates concerning consciousness.
} 
application is dependent on both (i) the nature of the term in question, and (ii) the context/debate in question, as dictated by heuristics (a) and (b), above. Sometimes a term should be eliminated from one context (where it is giving rise to confusion and verbal disputes), whilst being retained in other contexts. Sometimes a term might play a pivotal role in the arguments being put forward, but that term quite obviously does not have a number of different theoretical uses. More commonly a term might have several importantly different theoretical uses, but, in a particular debate, it might not play a pivotal role in the arguments being put forward. An important example here is our own use of 'concept' in this paper. Despite our firm belief that this term has fragmented in the way Machery (2009) and others have indicated, we use it freely in this paper. In this paper, we just do not put weight on 'concept' - that is to say, differences in the way 'concept' is used in some literature do not matter to the arguments put forward here. It is perfectly consistent, on pragmatic grounds, to advocate eliminativism about 'concept' in some contexts but not in others, since the term might be causing trouble in some contexts but not in others. This is what selective eliminativism is all about.

As another example consider the term 'hard'. In a 1942 work entitled Hardness and Hardness Measurements S. R. Williams asks the question: "Would it clarify our thinking if we eliminated the word "hardness" from our scientific vocabulary?" (cited in Wilson 2006, p.350). The question arises because in materials science the word 'hard' can mean a number of importantly different things, including scratchability, dentability, breakability, malleability, and machinability. Williams' answer is 'no', and Wilson (2006, p.350) agrees: "[T]he term will never vanish utterly from the colloquial vocabulary of anyone who works with materials." It is even more obvious that the term ought not to be eliminated from general colloquial vocabulary! But in a context in materials science where the differences between the sub-concepts really matter, there is just no point to using the word 'hard' - it does not communicate enough to help. And there is a danger that different interlocutors will interpret 'hard' in different ways and miscommunicate. Further, one just does not need the word 'hard' to communicate about materials - quite clearly, one can say everything one wants to say about materials using other terms such as those noted above.

Sensitivity to the selectivity of eliminativism can help resolve several debates which have taken place between 'pluralists' and 'eliminativists'. Usually these debates rest on the misguided assumption that eliminativism must be all or nothing: so often when eliminativism is discussed the question asked is whether the term in question should be completely eliminated from all discourse (or perhaps all professional discourse). Rejecting this assumption casts such debates in a new light. Consider the work of Ereshefsky. In earlier work (1992 and 1998) he was an advocate of the view that 'species' should be eliminated from biology, but in later work (2010b) he has changed his mind, and now argues against elimination. His argument against eliminativism revolves around the fact that the term 'species' is 'entrenched':

Students are taught the term from their earliest encounters in biology. Field guides and taxonomic monographs use the word 'species'. And the term is even found in our governments’ laws. (2010b, pp.420-421).

[T] here is no pressing need to eliminate 'species' from biology, as long as we are careful in how we use the term. (ibid.) 
For us, there are two issues here. Most obviously, if we are selective eliminativists we can agree that there is no pressing need to completely eliminate 'species' from biology. That is surely too radical, and not even possible. But the second clause of the latter quote indicates that Ereshefsky thinks the status quo is basically fine, and we can proceed business-as-usual so long as we are 'careful'. But we have already discussed why 'being careful' just will not do. As in so much of this literature, Ereshefsky assumes a dichotomy between total eliminativism and the status quo. But instead one can use our two heuristics to separate the contexts where we should be eliminativists, and those where we should not.

We claim that selective eliminativism allows us to accomodate all the considerations that originally drew Ereshefsky to eliminativism, and these new considerations which bring him to prefer the label 'pluralism'. In other words, the later Ereshefsky may be correct that there are some contexts where it would be pointless to eliminate a term given how entrenched it is, and how little trouble the term is causing within the context/ debate in question. But in other contexts it may be that the advantages of eliminating the term far outweigh the inconvenience of managing without it. ${ }^{28}$

This line of reasoning not only helps resolve conflicting considerations within a single person; it also helps to dissolve disputes between different philosophers in various different debates throughout philosophy of science. For example, in the 'concept' debate between Machery and his critics, Machery gives numerous good reasons to eliminate 'concept', and Weiskopf (2009) gives good reasons to retain it. However, Machery himself agrees that it should not be eliminated from all discourse (although he perhaps thinks it should be eliminated from all psychology - see Machery 2009, p.246), and Weiskopf does not provide an argument that it should never be eliminated. From the perspective of selective eliminativism this debate thus dissolves into a mere difference of emphasis, with Machery arguing for ways in which the term 'concept' can cause trouble, and Weiskopf arguing for ways in which it can be useful/ important. The same goes for Prinz's criticisms of Machery (e.g. Prinz 2010): much of the disagreement disappears if the claim is only that 'concept' should sometimes (often) be eliminated. And Machery (2009) gives some good examples of such contexts, even if, in the end, there are fewer such contexts than Machery suggests. This same line of thinking can be applied to debates between eliminativists and anti-eliminativists in any of the examples listed in Section 1.

To sum up, we argue that when a concept has undergone conceptual fragmentation, and fulfils heuristics (a) and (b), this is defeasible evidence for the view that we should embrace selective eliminativism about the term that corresponds to that concept. We also think that terms should be eliminated from debates far more often than they currently are. Which terms? Which debates? There is no recipe, but we refer the reader to the heuristics. The motivation for widespread eliminativism is the past record of philosophy of science, combined with the fact that subtle variations in the meaning of a scientific term (i) arise a lot, and (ii) can have very significant consequences for our debates. Importantly, because we do not advocate eliminating a term from all (professional) discourse, we sidestep the vast majority of arguments against eliminativism currently found in the literature.

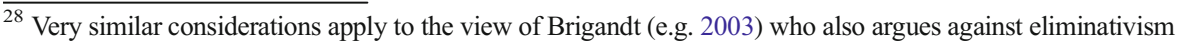
about 'species'.
} 


\section{Objections and replies}

(i) A role for 'natural kinds'?

In the literature one finds arguments for pluralism and eliminativism which put great weight on 'natural kinds' (see e.g. Griffiths 1997; Machery 2009; Irvine 2013). The arguments typically start with the claim that a certain term refers to a collection of entities that do not form a natural kind. Instead the term is an 'umbrella term', referring to a heterogenous collection of different entities. Then it is claimed that there exist several (sub)concepts each of which refers to a subclass of the collection of entities, and each of these subclasses forms a natural kind. Then the eliminativist takes another step and argues that the original umbrella term should be eliminated (because it does not refer to a natural kind), to be replaced with the terms for the subconcepts which do refer to natural kinds.

We think that motivating eliminativism by appeal to natural kinds, rather than theoretical pragmatics, presents unnecessary complications. Machery may think he needs to argue that 'concept' does not refer to a natural kind in order to fully justify eliminating use of that term. But actually, on close inspection, even Machery invokes pragmatic arguments to supplement his ontological ones. To start with, he accepts that not referring to a natural kind is not sufficient for eliminating a term - the term might nevertheless play 'a useful role'. ${ }^{29}$ We would add that, given the lessons of the previous section, it also is not necessary to argue that a term does not refer to a natural kind to have sufficient grounds for eliminating it. Again, what really matters is how useful eliminativism would be with regard to a given set of debates. Machery himself argues that using the term 'concept' causes confusion and miscommunication, encourages verbal disputes, and hinders useful classification. We just do not need any ontological claims to justify eliminativism, and under these circumstances one would do better to simply stay silent on the complex and controversial issues involving 'natural kinds'. 30

We do not wish to claim that appeal to natural kinds is never a useful way to explain fragmentation (e.g. the case of jade). Our point is simply that arguments which put weight on natural kinds usually themselves also put weight on theoretical pragmatics (e.g. Kim 1992; Machery 2005). But not vice versa. One can add to these considerations the difficulties that arise if it turns out that NATURAL KIND is itself subject to conceptual fragmentation. It is increasingly common to see pluralism explicitly defended vis-à-vis 'natural kind' (e.g. Dupré 1993, p.28 ff.; Ereshefsky 1992a, 2001).

\section{(ii) Definitions for subconcepts?}

A different line of objection concerns the question whether the 'fragments', the subconcepts, can themselves be defined. Suppose a concept fragments naturally within a field of investigation, and we end up with different subconcepts. According to what we have already said about the 'death of definitionism' it will not be possible to provide definitions for these subconcepts (just as it wasn't possible for the original superordinate concept). That is, any definition we could put forward would not precisely capture

\footnotetext{
${ }^{29}$ See e.g. Machery 2005, p.465: "A theoretical term that has been found to fail to pick out a natural kind should be kept if it plays a useful role."

${ }^{30}$ Similar considerations persuade us to avoid putting weight on reference.
} 


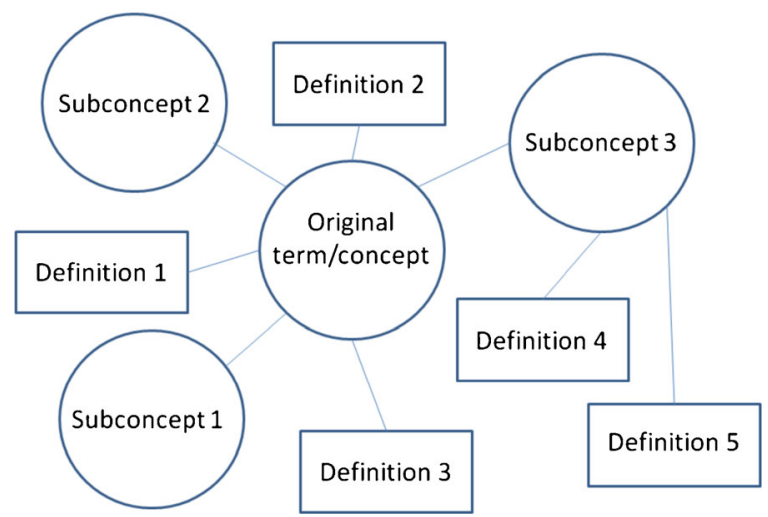

Fig. 1 One example of how the complex web of concepts, subconcepts, and definitions might look

the content of a given subconcept. We can of course provide stipulative definitions, but these will never line up exactly with the subconcepts. We may even find ourselves with more than one definition of a single subconcept (see Fig. 1). Two worries in particular may arise here: (i) how can we justify using stipulative definitions if they cannot capture the content even of the subconcepts? And also: (ii) how can one eliminate a concept the content of which cannot be captured even by a range of different definitions?

In our view this is not so much an objection as a way of revealing just how complex things can get when we consider the relationship between terms, concepts, and definitions. We accept that an original superordinate term will sometimes fragment into subterms, and a superordinate concept will sometimes fragment into subconcepts, and in addition one can introduce a range of definitions for the terms, and none of these things will match up perfectly. ${ }^{31}$ However, within the context of a specific debate a term (or subterm) will be doing work of some kind, and this work will only depend on some aspect of the content of the corresponding concept. As an example consider the concept SPORT: if two people are debating whether chess is a sport, then probably what really matters to their disagreement is whether a sport must necessarily demand physical skill of its participants. We can choose to interpret one of the interlocutors as employing a concept of SPORT $_{1}$ whereby a sport necessarily requires physical skill. In that case chess is not a sport, and the aspect of the concept $\mathrm{SPORT}_{1}$ which matters in this context is the aspect which tells us that a sport must involve some physical skill. And, crucially, this feature can be captured in a definition of 'sport', even if there can be no 'perfect' definition of either SPORT or its subconcepts.

This is an example from outside science, of course, but it illustrates our general claim. Stipulative definitions can fulfil certain particular theoretical roles, and bring to the surface the aspect of a concept which was actually being used within a certain debate. They needn't perfectly capture the content of any concept (or subconcept) in order to do this, and they need not be able to fulfil all of the

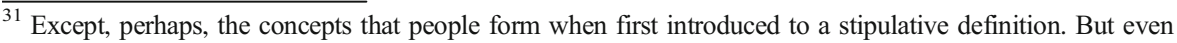
this is not clear cut.
} 
theoretical roles that the concept has been expected to fulfil since, as we have argued, there will often be a great many such roles. ${ }^{32}$

\section{Conclusion}

Philosophers of science have often spent much energy attempting to answer questions of the form 'What is $\mathrm{x}$ ?' for some $\mathrm{x}$ or another. In this paper we have argued that a great many such debates are based on the false assumption that there is one, single thing that $\mathrm{x}$ is. A great many more debates are premised on the idea that some $\mathrm{x}$ is a single thing (e.g. 'Is a $y$ an $x$ ?'). If we are right that, in general, we should expect most scientific concepts to fragment, then it is hard to escape the conclusion that a deplorable amount of energy has been spent asking bad questions.

One can start to put a positive spin on this, however, if one accepts that many of the definitions/theories of $\mathrm{x}$ that have been put forward remain useful for certain purposes, in certain contexts. For the pluralist, such a definition - originally put forward in the spirit of monism - can be embraced as just one of the plurality of different definitions of $x$. For the eliminativist, such a definition might remain useful not as a definition of $\mathrm{x}$, but as a stipulative definition put forward to do a specific job within a specific context. And we have seen several examples of just this sort of phenomenon in this paper.

Nevertheless, despite the usefulness of many definitions/theories put forward in the spirit of monism, the default assumption should be that any given scientific concept fragments. If philosophical debates proceed in this spirit we will take a significant step towards:

(i) avoiding many bad questions and misguided projects,

(ii) avoiding placing too much weight on certain key concepts/definitions in the projects which are not misguided.

We will take another significant step forward if we eliminate terms from our debates much more often in accordance with heuristics (a) and (b). This entails leaving behind some questions, and asking new questions. And it entails making claims in new ways. Perhaps the most obvious example we have seen is Frisch's claim that 'classical electrodynamics is inconsistent', especially since Frisch later came to regret stating his claim in this way. The temptation here, as elsewhere in philosophy, is to make bold and dramatic, remarkable claims. Frisch's claim as stated is eyecatching, and demanded a response from the community. By contrast, it is much harder

\footnotetext{
$\overline{32}$ What of the thought (with thanks to an anonymous reviewer here) that (nearly) all subconcepts are born of stipulative definitions, such that there is a perfect match between most (sub)concepts and the definitions that gave rise to them? This view strikes us as implausible: we disagree strongly with a vision of (philosophy of) science as full of concepts which can be perfectly defined by simply identifying the stipulative definitions which gave rise to them. This would make nonsense of the fact that academics are embroiled in debates concerning the best way(s) to define various concepts, including in particular the twenty concepts listed in Section 1. Even discounting that, we reject this view since we think it makes more sense to think of a stipulative definition of 'biospecies' (say) as inspired not by a general SPECIES concept possessed by the definer, but rather by a particular subconcept BIOSPECIES already possessed by the definer in advance of providing the definition.
} 
to convince one's audience that a statement is interesting and important if it takes the form: ' $y$ (on one interpretation) is $x$ (on one interpretation)'. It is still harder if ' $y$ ' and ' $x$ ' do not feature in the statement at all. But in philosophy it is the hard road that leads forward.

Acknowledgments The authors would like to thank audiences at the Universities of Durham, York and Manchester for discussion of the material for the paper. We would particularly like to thank David Chalmers and David Liggins. Special thanks to one anonymous referee who pushed us on a variety of issues, and helped us to improve the paper. HT would like to thank the Royal Institute of Philosophy for a Jacobsen Fellowship, which provided support while the paper was being written, and the Leverhulme Trust and the Isaac Newton Trust for an Early Career Fellowship (ECF-2015-088), which provided support while the revisions on the paper were carried out.

Open Access This article is distributed under the terms of the Creative Commons Attribution 4.0 International License (http://creativecommons.org/licenses/by/4.0/), which permits unrestricted use, distribution, and reproduction in any medium, provided you give appropriate credit to the original author(s) and the source, provide a link to the Creative Commons license, and indicate if changes were made.

\section{References}

Allport, A. (1993). Attention and control. Have we been asking the wrong questions? A critical review of twenty-five years. In D. E. Meyer, and S. Kornblum (eds.), Attention and performance, XIV (pp.183218). Cambridge, MA: MIT Press.

Anderson, B. (2011). There is no such thing as attention. Frontiers in Psychology, 2, 1-8.

Andreasen, R. O. (2000). 'Race: biological reality or social construct?' philosophy of science, 67(proceedings), S653-S666.

Baddeley, A., Eysenck, M., \& Anderson, M. (2009). Memory. New York: Psychology Press. Reprinted, 2010.

Beall, J. C., \& Restall, G. (2006). Logical pluralism. Oxford: Oxford University Press.

Belot, G. (2007). Is classical electrodynamics an inconsistent theory? Canadian Journal of Philosophy, 37, 263-282.

Blaxter, M. (2004). Health. Hong Kong: Polity.

Brigandt, I. (2003). Species pluralism does not imply species eliminativism. Philosophy of Science, 70, 13051316.

Block, N. (1995) How many concepts of consciousness? reprinted as Ch.10, pp.215-247 in consciousness, function and representation: collected papers, volume 1. USA: MIT Press, 2007.

Capek, V. and D. Sheehan (2005): Challenges to the second law of thermodynamics. Springer.

Carel, H. (2008): Illness: the cry of the flesh. Acumen.

Carnap, R. (1945). The two concepts of probability. Philosophy and Phenomenological Research, 5(4), 513532.

Carston, R. (2002). Thoughts and utterances: the pragmatics of explicit communication. Oxford: Blackwell.

Chalmers, D. J. (2011). Verbal disputes. The Philosophical Review, 120(4), 515-566.

Churchland, P. (1981). Eliminative materialism and the propositional attitudes. Journal of Philosophy, 78(2), 67-90.

Clark, H., \& Gerrig, R. (1983). Understanding old words with new meanings. Journal of Verbal Learning and Verbal Behavior, 22, 591-608.

Cooper, R. (2002). Disease. Studies in History and Philosophy of Biological and Biomedical Sciences, 33(2), 263-282.

Currie, A. and Killin, A. (forthcoming). Music pluralism and the science of music. European Journal for the Philosophy of Science. 6(1), 9-30.

Duncan, J. (2006). Brain mechanisms of attention. The Quarterly Journal of Experimental Psychology, 59, 2-27.

Dupré, J. (1993). The disorder of things. Cambridge, MA: Harvard University Press.

Ereshefsky, M. (1992a). Eliminative pluralism. Philosophy of Science, 59(4), 671-690.

Ereshefsky, M. (1992b). The units of evolution: essays on the nature of species. Cambridge, MA.: MIT Press.

Ereshefsky, M. (1998). Species pluralism and anti-realism. Philosophy of Science, 65(1), 103-120.

Ereshefsky, M. (2001). The poverty of the Linnaean hierarchy: A philosophical study of biological taxonomy. USA: Cambridge University Press. 
Ereshefsky, M. (2010a). Microbiology and the species problem. Biology and Philosophy, 25, 553-568.

Ereshefsky, M. (2010b). Darwin's solution to the species problem. Synthese, 175, 405-425.

Ereshefsky, M., \& Reydon, T. A. C. (2015). Scientific kinds. Philosophical Studies, 172(4), 969-986.

Fauconnier, G., \& Turner, M. (2002). The Way We think: conceptual blending and the mind's hidden complexities. New York: Basic Books.

Fletcher, S. (2012). What counts as a Newtonian system? The view from Norton's dome. European Journal for Philosophy of Science, 2, 275-297.

Fodor, J. (1981). The present status of the innateness controversy, in Representations: Philosophical essays on the foundations of cognitive science. (Cambridge, MA: MIT Press). pp.257-316.

Fodor, J. (1998). Concepts: where cognitive science went wrong. New York: Oxford University Press.

Frisch, M. (2005). Inconsistency, asymmetry and non-locality. Oxford: OUP.

Frisch, M. (2008). Conceptual problems in classical electrodynamics. Philosophy of Science, 75, 93-105.

Glasgow, J. M. (2003). On the new biology of race. The Journal of Philosophy, 100(9), 456-474.

Griffiths, P. E. (1997). What emotions really Are: The problem of psychological categories. Chicago: University of Chicago Press.

Griffiths, P. E. (2002). What is innateness? The Monist, 85(1), 70-85.

Hardimon, M. O. (2003). The ordinary concept of race. The Journal of Philosophy, 100(9), 437-455.

Hendry, R. F. (2005). Lavoisier and Mendeleev on the elements. Foundations of Chemistry, 7, 31-48.

Hendry, R. F. (2008). Two conceptions of the chemical bond. Philosophy of Science, 75, 909-920.

Hennig, W. (1966). Phylogenetic systematics. Urbana: University of Illinois Press.

Hesslow, G. (1993). Do we need a concept of disease? Theoretical Medicine, 14(1), 1-14.

Hill, C. (2009). Consciousness. New York: Cambridge University Press.

Howe, M. J. A. (1990). Does intelligence exist?, The psychologist, November Issue: pp.490-493.

Irvine, E. (2013). Consciousness as a scientific concept: a philosophy of science perspective. Dordrecht: Springer.

Jackendoff, R. (1992). Languages of the mind. Cambridge, MA: MIT Press.

Kim, J. (1992). Multiple realization and the metaphysics of reduction. Philosophy and Phenomenological Research, 52(1), 1-26.

Kitcher, P. (1984). Species. Philosophy of Science, 51, 308-333.

Lasersohn, P. (1999). Pragmatic halos. Language, 75, 522-551.

Machery, E. (2005). Concepts are not a natural kind. Philosophy of Science, 72(3), $444-467$.

Machery, E. (2009). Doing without concepts. New York: Oxford University Press.

Machery, E. (2012). Why I stopped worrying about the definition of life... and why you should as well. Synthese, 185, 145-164.

Magnus, P. D. (2012). What SPECIES can Teach us About THEORY, Unpublished Manuscript. Available here: http://www.fecundity.com/job/paper.php?item=speciesanalogy

Malament, D. B. (2008). Norton's slippery slope. Philosophy of Science, 75, 799-816.

Margolis, E., \& Laurence, S. (1999). Concepts: core readings. MIT Press.

Maroney, O. J. E. (2007). The Physical Basis of the Gibbs-von Neumann entropy, available Here: http:/arxiv. org/abs/quant-ph/0701127

Mayr, E. (1970). Populations, species, and evolution. Cambridge, MA: Harvard University Press.

Mix, J. L. (2015). Defending definitions of life. Astrobiology, 15(1), 15-19.

Muller, F. A. (1997). ). The equivalence myth of quantum mechanics: part I. Studies in History and Philosophy of Modern Physics, 28(1), 35-61.

Muller, F. A. (2011). Reflections on the revolution at Stanford. Synthese, 183(1), 87-114.

Murphy, G. (1997). Polysemy and the creation of novel word meanings, pp.235-265 in Ward, T., Smith, S. \& Vaid, J. (eds.) Creative Thought: An Investigation of Conceptual Structures and Processes. Washington DC: American Psychological Association.

Needham, P. (1972). Belief, language, and experience. Chicago: University of Chicago Press.

Newton-Smith, W. H. (2001). A companion to the philosophy of science. Wiley-Blackwell.

Percival, P. (2000). Probability, Ch.53 in W. H. Newton-Smith (ed.) A Companion to the Philosophy of Science. Blackwell.

Plutynski, A. (2004). Explanation in classical population genetics. Philosophy of Science, 71, 1201-1214.

Prinz, J. (2010). Can concept empiricism forestall eliminativism? Mind \& Language, 25(5), 612-621.

Rey, G. (2010). Concepts versus conceptions (again). Behavioral and Brain Sciences, 33(2/3), $221-222$.

Sankey, H. (2000): Methodological Pluralism, Normative Naturalism and the Realist Aim of Science, in R. Nola, H. Sankey (eds.) After Popper, Kuhn and Feyerabend: Recent issues in theories of scientific method, Australasian Studies in the History and Philosophy of Science $\mathbf{1 5 .}$ 
Sankey, H. (2010): Scientific Method, in P. Psillos and M. Curd (eds.) The Routledge Companion to the Philosophy of Science: Routledge.

Schlinger, H. D. (2003). The myth of intelligence. The Psychological Record, 53, 15-32.

Skow, B. (2014). Are there Non-causal explanations (of particular events)? British Journal for the Philosophy of Science, 65(3), 445-467.

Shoemaker, D. W. (2007). Personal identity and practical concerns. Mind, 116(462), 317-357.

Sidelle, A. (2007). The method of verbal dispute. Philosophical Topics, 35, 83-113.

Sligte, I. G., Scholte, S., \& Lamme, V. A. F. (2008). Are there multiple visual short-term memory stores? PloS One, 3(2), e1699. doi:10.1371/journal.pone.0001699.

Sligte, I. G., Scholte, S., \& Lamme, V. A. F. (2009). V4 activity predicts the strength of visual short term memory representations. The Journal of Neuroscience, 29(23), 7432-7438.

Stanford, K., \& Kitcher, P. (2000). Refining the causal theory of reference for natural kind terms. Philosophical Studies, 97, 99-129.

Styles, E. (1997). The psychology of attention. Cornwall: Psychology Press.

Taylor, J. H. (2015a). Against unifying accounts of attention. Erkenntnis, 80(1), 39-56.

Taylor, J. H. (2015b). Consciousness and the Heterogeneity of Attention. Unpublished PhD thesis, University of Durham, UK.

Taylor, P. C. (2000). Appiah's uncompleted argument: W. E. B. Du bois and the reality of race. Social Theory and Practice, 26(1), 103-128.

Thagard, P. (1990). Concepts and conceptual change. Synthese, 82(2), 255-274.

Uidhir, C. M., \& Magnus, P. D. (2011). Art concept pluralism. Metaphilosophy, 42(1-2), 83-97.

Vickers, P. (2013). Understanding inconsistent science. OUP.

Vickers, P. (2014). Scientific theory eliminativism. Erkenntnis, 79(1), 111-126.

Weiskopf, D. (2009). The plurality of concepts. Synthese, 169, 145-173.

Wilson, M. (2006). Wandering significance. Oxford: OUP.

Wilson, M. (2009). Determinism and the mystery of the missing physics. British Journal for the Philosophy of Science, 60, 173-193.

Wilson, D., \& Carston, R. (2007). A unitary approach to lexical pragmatics: relevance, inference and ad Hoc concepts. In N. Burton-Roberts (Ed.), Pragmatics (pp. 230-259). London: Palgrave.

Woodward, J. (2014). Scientific Explanation. The Stanford Encyclopedia of Philosophy (Winter 2014 Edition), Edward N. Zalta (ed.); URL = <http://plato.stanford.edu/archives/win2014/entries/scientific-explanation/>.

Wright, L. (1973). Functions. Philosophical Review, 82, 139-168.

Wu, W. (2011). Attention as selection for action, pp.97-116 in C. Mole., W. Wu and D. Smithies (eds.), Attention: Philosophical and Psychological Essays. New York: Oxford University Press. 